\title{
ВMJ Global Health Burden of cardiovascular diseases associated with fine particulate matter in Beijing, China: an economic modelling study
}

\author{
Yawen Jiang (D) , ${ }^{1}$ Shan Jiang (D) , ${ }^{2}$ Weiyi $\mathrm{Ni}^{3}$
}

To cite: Jiang Y, Jiang S, Ni W. Burden of cardiovascular diseases associated with fine particulate matter in Beijing, China: an economic modelling study. BMJ Global Health 2020;5:e003160. doi:10.1136/ bmjgh-2020-003160

Handling editor Lei Si

- Additional material is published online only. To view, please visit the journal online (http://dx.doi.org/10.1136/ bmjgh-2020-003160).

Received 14 June 2020 Revised 7 September 2020 Accepted 9 September 2020

Check for updates

(c) Author(s) (or their employer(s)) 2020. Re-use permitted under CC BY-NC. No commercial re-use. See rights and permissions. Published by BMJ.

${ }^{1}$ School of Public Health (Shenzhen), Sun Yat-sen University, Shenzhen, Guangdong, China

${ }^{2}$ School of Population and Public Health, The University of British Columbia, Vancouver, British Columbia, Canada

${ }^{3}$ Department of Pharmaceutical and Health Economics,

University of Southern California Los Angeles, California, USA

Correspondence to

Dr Yawen Jiang;

jiangyw26@mail.sysu.edu.cn

\section{ABSTRACT}

Objective To evaluate the economic and humanistic burden associated with cardiovascular diseases that were attributable to fine particulate matter $\left(\leq 2.5 \mu \mathrm{g} / \mathrm{m}^{3}\right.$ in aerodynamic diameter; $\mathrm{PM}_{2.5}$ in Beijing.

Methods This study used a health economic modelling approach to compare the actual annual average $\mathrm{PM}_{25}$ concentration with the $\mathrm{PM}_{25}$ concentration limit $\left(35 \mu \mathrm{g} / \mathrm{m}^{3}\right)$ as defined by the Chinese Ambient Air Quality Standard in terms of cardiovascular disease outcomes in Beijing adult population. The outcomes included medical costs, qualityadjusted life-years (QALYS) and net monetary loss (NML). Beijing annual average $\mathrm{PM}_{25}$ concentration was around $105 \mu \mathrm{g} / \mathrm{m}^{3}$ during 2013-2015. Therefore, we estimated the differences in cardiovascular outcomes of Beijing adults between exposure to the $\mathrm{PM}_{25}$ concentration of $105 \mu \mathrm{g} / \mathrm{m}^{3}$ and exposure to the concentration of $35 \mu \mathrm{g} / \mathrm{m}^{3}$. According to WHO estimates, the hazard ratios of coronary heart disease and stroke associated with the increase of $\mathrm{PM}_{2.5}$ concentration from 35 to $105 \mu \mathrm{g} / \mathrm{m}^{3}$ were 1.15 and 1.29 , respectively.

Results The total 1-year excess medical costs of cardiovascular diseases associated with $\mathrm{PM}_{25}$ pollution in Beijing was US\$147.9 million and the total 1-year QALY loss was 92574 in 2015, amounting to an NML of US\$2281.8 million. The expected lifetime incremental costs for a male Beijing adult and a female Beijing adult were US\$237 and US\$163, the corresponding QALY Ioss was 0.14 and 0.12 , and the corresponding NML was US $\$ 3514$ and US\$2935.

Conclusions $\mathrm{PM}_{2.5}$-related cardiovascular diseases imposed high economic and QALY burden on Beijing society. Continuous and intensive investment on reducing $\mathrm{PM}_{25}$ concentration is warranted even when only cardiovascular benefits are considered.

\section{INTRODUCTION}

Long-term exposure to ambient fine particulate matter $\left(\leq 2.5 \mu \mathrm{g} / \mathrm{m}^{3}\right.$ in aerodynamic diameter; $\mathrm{PM}_{2.5}$ ) has been linked to increased morbidity and mortality. ${ }^{1}{ }^{2}$ WHO Global Burden of Disease (GBD) project estimated that over 3.2 million premature deaths worldwide and approximately 2.0 million

\section{Key questions}

What is already known?

- There is ample evidence that PM2.5 air pollution increases cardiovascular disease risk.

What are the new findings?

- The total one-year excess medical costs of cardiovascular diseases associated with PM2.5 pollution in Beijing was US\$147.9 million and the total one-year QALY loss was 92574 in 2015, amounting to an NML of US\$ 2281.8 million.

\section{What do the new findings imply?}

- Continuous and intensive investment on reducing PM2.5 concentration may be warranted even when only cardiovascular benefits are considered.

premature deaths in East Asia were attributable to ambient air $\mathrm{PM}_{25}$ pollution in 2010 . The impact of $\mathrm{PM}_{25}$ pollution in China is particularly substantial because of the severe pollution level and the population size ${ }^{4}$ and has drawn increasing concerns in recent years. ${ }^{56}$

An important reason high $\mathrm{PM}_{25}$ concentration leads to excess morbidity and mortality is that it increases the risks of cardiovascular diseases. ${ }^{78}$ In fact, a previous study on Chinese population in Hong Kong found statistically significant association between $\mathrm{PM}_{2.5}$ increase and both coronary heart disease (CHD) and stroke. ${ }^{1}$ Hence, it is important to estimate the corresponding economic burden of cardiovascular diseases attributable to $\mathrm{PM}_{2.5}$. Such estimates can provide the foundation for policymaking in the aspects of cardiovascular disease management and environment protection. Beijing, the capital city of China and one of the largest metropolitan areas in the world, is located in an area (BeijingTianjin-Hebei) having the highest annual average $\mathrm{PM}_{25}$ concentration in China. ${ }^{9}$ The 
hazy weather in Beijing has often been featured in global media reports. ${ }^{10} 11$ However, the economic and humanistic burden of cardiovascular diseases in Beijing associated with $\mathrm{PM}_{2.5}$ has not been specifically documented in literature so far.

By focusing on a specific disease area, economic modelling allows estimates of direct medical costs and quality-adjusted life-year (QALY) loss. A QALY is a life year weighted by utility that quantifies individuals' or societies' preference for a health state. ${ }^{12}$ Utility is assessed on a scale of which 0 represents death and 1 represents full health. Accordingly, the decrement of utility is disutility. ${ }^{13}$ Reliable and thorough quantification of the disease-specific burden can be critical for policymakers to understand the priority of resource allocation to pollution reduction and cardiovascular disease treatment. As such, the current study aimed to evaluate both excess direct medical costs and QALY loss associated with cardiovascular diseases that were attributable to $\mathrm{PM}_{2.5}$ pollution in Beijing using a health economic approach.

\section{METHODS \\ Model}

This study used an economic modelling approach that was borrowed from health economic evaluations. In a health economic evaluation, a model simulates alternative courses of action to compare interventions in terms of healthcare costs and health outcomes. ${ }^{14}$ The current study did not aim to evaluate a specific medical or policy intervention. Instead, it compared cardiovascular disease outcomes in terms of healthcare costs and QALY of Beijing adult population when exposed to alternative levels of ambient air $\mathrm{PM}_{2.5}$ pollution. Otherwise, it was the same as a health economic evaluation. The model was constructed from the societal perspective.

We created a patient-level discrete-time microsimulation model that allowed age-varying event probabilities and the occurrence of competing events in each cycle. ${ }^{15-17}$ The model advanced at a yearly cycle and simulated three cardiovascular events in each cycle: acute myocardial infarction (AMI), stroke and unstable angina. Several previous cardiovascular modelling studies in both Chinese and non-Chinese settings used the same set of events and showed that these three events imposed sizeable burden on healthcare systems. ${ }^{18}{ }^{19} \mathrm{In}$ addition to the cardiovascular events, the model simulated background mortality as an independent event in each cycle to be consistent with the literature. ${ }^{18-21}$ When one or multiple events happened in a cycle, the model calculated corresponding costs and QALY loss, re-evaluated the mortality rate, and updated disease history. Each simulated individual started at 18 years old without any prevalent cardiovascular events, iterated through cycles, and ended at either death or turning 90 years old. The costs and QALYs up to death or 90 years old were accrued across cycles accordingly. To estimate the incremental economic burden and QALY loss associated with cardiovascular diseases that were attributable to $\mathrm{PM}_{2.5}$ air pollution, we conducted the simulation using the actual annual average pollution level in the years 2013-2015 and a relatively low pollution level which was the maximum reasonable $\mathrm{PM}_{2.5}$ concentration as defined by air quality standards. Then we compared the individual average lifetime costs and QALY results from the two alternative courses. A flow chart of the model structure is shown in figure 1, additional information of the modelling methodology has been provided elsewhere. ${ }^{22}$ Each course of simulation modelled 10000 individuals.

\section{Cardiovascular disease risk calculation and data inputs}

Our model used a cardiovascular risk equation from a previous epidemiology study in China (online supplemental materials part 1). ${ }^{23}$ This equation took as inputs a set of risk factors including age, systolic blood pressure (SBP), total cholesterol (TC), body mass index (BMI), smoking and diabetes. The output of the equation was a predicted 10-year integrated probability of AMI and stroke. To use the risk prediction in yearly cycles, the 10 -year probability was transferred into its 1-year equivalent using the declining exponential approximation of life expectancy (DEALE) method (online supplemental materials part 2). ${ }^{24}$ The 1-year probability of AMI was then calculated using the 1-year integrated probability of AMI and stroke and the relative incidence of AMI to the composite of AMI and stroke (online supplementary materials part 3) ${ }^{23}$ The 1-year probability of stroke was calculated similarly. The 1-year probability of unstable angina was determined using the age-specific ratio of unstable angina incidence to stroke incidence in China (online supplemental material part 4 and online supplemental table S1).$^{25}$ For each of the events in each cycle, a random number between 0 and 1 from a uniform distribution was generated to be compared with the probability of the given event, which was judged to be incurred if the random number was smaller than the probability and absent otherwise. Probabilities were updated at the beginning of each cycle. We used Beijing-specific data for SBP, TC and BMI, ${ }^{26}{ }^{27}$ and used overall Chinese population data for smoking and diabetes (online supplemental materials part 5 and online supplemental table S2) because Beijing-specific overall adult smoking information and diabetes prevalence and incidence information were absent in the literature. ${ }^{28}$

For each simulated individual, BMI was sampled once from the distribution of Beijing male BMI at the age of 43.4 years or female BMI at the age of 44.3 years. ${ }^{26}$ Following that, the BMI at a certain age in the model was calculated using the relationship between BMI and age in China that was previously estimated in the literature (online supplemental materials part 6) ${ }^{26}{ }^{29} \mathrm{SBP}$ was calculated using a similar approach. To enable such calculation, we estimated the relationship between SBP and age using data from the 2013 wave of the China Health and Retirement Longitudinal Study (online supplemental materials part 7). ${ }^{30} \mathrm{TC}$ input values by age group 


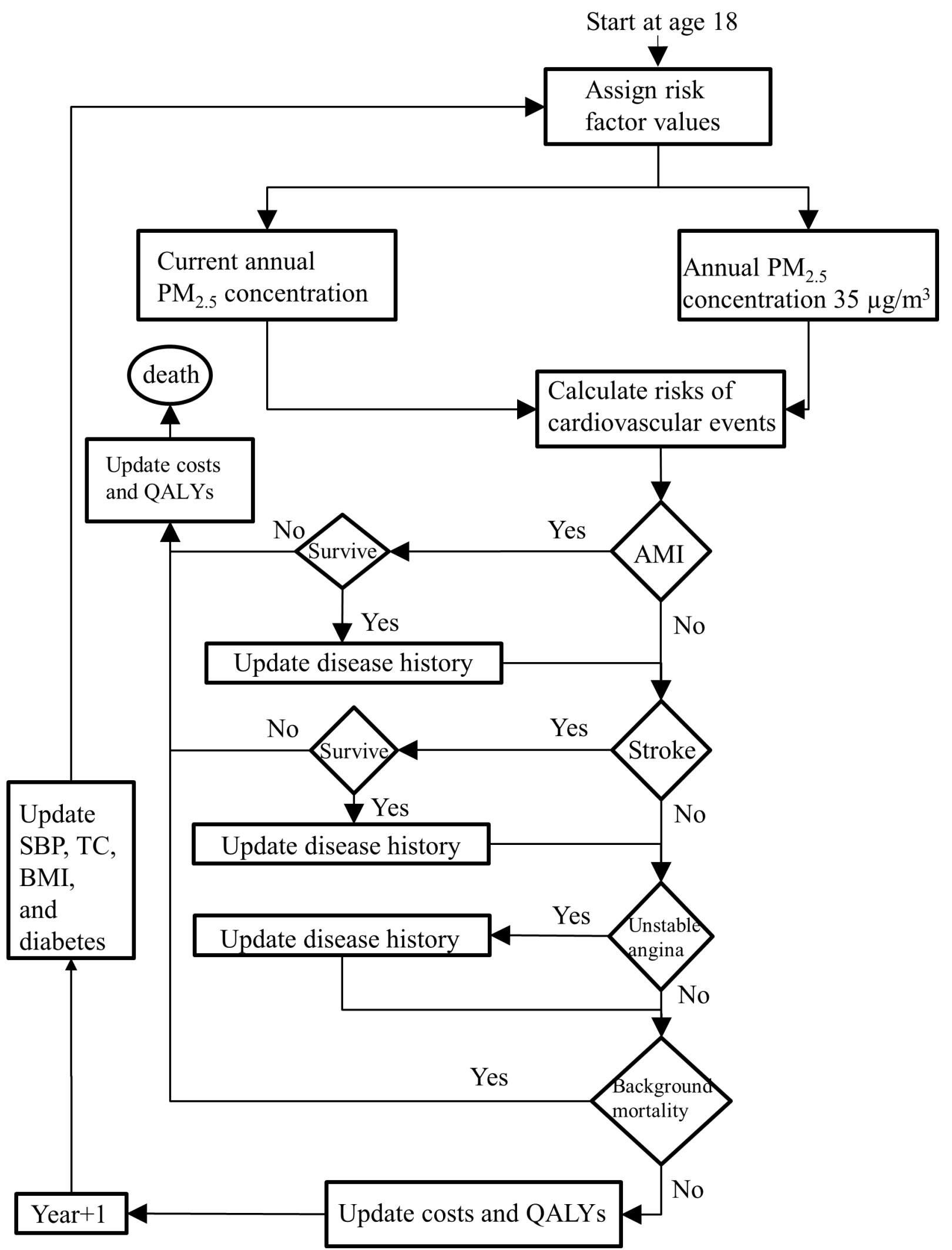

Figure 1 Flow chart of the discrete time microsimulation model. The simulation of individuals started at 18 years old, progressed at 1- year increment, and ended at death or 90 years old. AMI, acute myocardial infarction; BMI, body mass index; PM 25, particulate matter; QALY, quality-adjusted life years; SBP, systolic blood pressure; TC, total cholesterol.

were extracted from an epidemiology study. ${ }^{27}$ Smoking was determined only once for the lifetime at the beginning of the simulation of each individual. ${ }^{28}$ The model also determined whether a given individual had diabetes at the age of 18 using the diabetes prevalence data for Chinese children. ${ }^{31}$ For those who did not have diabetes 
at the beginning cycle, their diabetes status was evaluated again in the next cycle using age-specific diabetes incidence data. ${ }^{28}$ The diabetes re-evaluation process was iterated in all subsequent cycles for those who did not have diabetes up to the previous cycle. Table 1 lists data inputs of risk factors.

\section{$\mathrm{PM}_{2.5}$ air pollution level and effect of $\mathrm{PM}_{2.5}$ on cardiovascular event risk}

The calculated event risks using the risk equation and data inputs described in the section above represented the risks as the status quo. Studies in the literature suggested that the annual average concentration of $\mathrm{PM}_{2.5}$ was in the range of $100-105 \mu \mathrm{g} / \mathrm{m}^{3}$ in Beijing from 2013 to 2015. ${ }^{3233}$ The Chinese Ambient Air Quality Standards (CAAQS) set the grade II standard of annual average $\mathrm{PM}_{2.5}$ concentration at $35 \mu \mathrm{g} / \mathrm{m}^{3}{ }^{4}{ }^{34}$ As such, the current analysis evaluated the excess economic burden and QALY loss associated with cardiovascular diseases that could be avoided if the annual average concentration of $\mathrm{PM}_{25}$ in Beijing was decreased from 105 to 35 $\mu \mathrm{g} / \mathrm{m}^{3}$. To accomplish this, it was necessary to apply the cardiovascular effect of $\mathrm{PM}_{2.5}$ to cardiovascular event risk calculation. We used the hazard ratios (HR) of CHD and stroke associated with $\mathrm{PM}_{2.5}$ increase estimated by WHO using an integrated exposure response (IER) approach, the latest estimates of which available on the GBD official website were from the 2010 GBD. ${ }^{35}$ Per the WHO IER estimates, the HRs of CHD and stroke were 1.15 and 1.29 if the ambient $\mathrm{PM}_{2.5}$ concentration was increased from 105 to $35 \mathrm{\mu g} / \mathrm{m}^{3}$. In the simulation course of low pollution, the reciprocals of HRs were multiplied by the status quo CHD and stroke event risks.

\section{Mortality}

Background mortality data by age were obtained from WHO country-specific lifetables. ${ }^{36}$ In the model, mortality was affected by an AMI or stroke event in both short and long terms. In the short term, an individual who had an AMI or stroke experienced 28-day excess mortality. ${ }^{19} 37$ The 28-day excess mortality rate was age varying. ${ }^{19}$ In the long term, an individual who had any prevalent AMI or stroke or both experienced excess morality subsequently which were two times of background mortality if new AMI or stroke events did not happen. ${ }^{38}$ Mortality inputs are listed in table 2.

\section{Outcome measures and inputs}

The outcomes of interest in the current study were direct medical costs and QALYs. Direct medical costs included hospitalisation costs, first-year long-term costs, and subsequent year outpatient visit costs (table 2). AMI and stroke survivors were assumed to require one office visit each year in their residual lifetime, whereas individuals with a history of unstable angina required one office visit each year up to a duration of sequelae that varied with the age of angina occurrence and the sex of the individual (online supplemental materials part 8 and online supplemental table S3) ${ }^{37}$ Costs were first inflated to 2015 Chinese currency using the China Healthcare Component Consumer Price Indices and then converted to 2015 US\$ using currency conversion rate in the same year. ${ }^{39} 40$ The calculation of QALYs used both age-specific utility weights and event-related disutility weights (table 2 ). The source of age-specific utility weights was from a national health services survey in China using EuroQol five dimensions questionnaire. ${ }^{41}$ The 1-month acute disutility weights associated with AMI and stroke and the disutility weight associated with angina were obtained from WHO GBD project. ${ }^{42}$ Post-AMI and poststroke disutility weights were obtained from a quality of life study on Chinese population with chronic conditions and WHO GBD project, respectively. ${ }^{43}$ In addition, the aforementioned duration of angina sequelae also applied to angina disutility.

We summarised the costs and QALYs using two distinct metrics. First, we calculated the 1-year total excess cardiovascular disease costs and QALY loss of the entire Beijing adult population that were attributable to $\mathrm{PM}_{25}$ pollution in 2015 (illustrated in online supplemental figure S1). To calculate this, we extracted yearly average incremental costs and QALY loss of each age group for male and female population, multiplied these results with the population of each corresponding age-sex group (online supplemental materials part 9 and online supplemental table S4) in Beijing, ${ }^{45}$ and summed the results across age-sex groups. The outcomes were not discounted because they were only evaluated in a 1-year time frame. Second, we simulated the lifetime courses of an 18-year-old Beijing male and female to calculate the individual expected lifetime excess cardiovascular disease costs and QALY loss attributable to $\mathrm{PM}_{2.5}$ pollution of male and female adults, respectively. The individual expected lifetime estimates resemble the concept of healthy life expectancy, they represent the average incremental costs and QALY loss that an 18-year-old individual is expected to have in the residual lifetime using current information on all age groups. The calculation of expected lifetime outcome values used an annual discount rate of $3 \% .{ }^{46}$

In addition, we calculated the net monetary loss (NML) associated with cardiovascular diseases that were attributable to $\mathrm{PM}_{2.5}$ pollution for both metrics. The NML was the sum of direct medical costs and monetised QALY loss. It is common to monetise QALYs in health economic analysis to better understand cost-benefit. ${ }^{48}$ Per WHO recommendations, the willingness to pay (WTP) to monetise each QALY was three times of China gross domestic product (GDP) per capita in $2014{ }^{4950}$ Consequently, the WTP for a QALY in the current study was US\$23 051.

\section{Alternative scenarios and sensitivity analyses}

An additional analysis examined the changes in results using an alternative scenario of reducing the annual average $\mathrm{PM}_{2.5}$ concentration to $15 \mu \mathrm{g} / \mathrm{m}^{3}$ because both the CAAQS grade I standard and the United States National Ambient Air Quality Standards secondary 
Table 1 Risk factor inputs

\section{Risk factor type}

$\mathrm{SBP}(\mathrm{mm} \mathrm{Hg})$

SBP of 43.4 years old men

SBP of 44.3 years old women

Men TC (mmol/L)

$\begin{array}{ll}\text { Age } 18-19 & 3.38 \\ \text { Age } 20-24 & 4.01 \\ \text { Age 25-29 } & 4.26 \\ \text { Age 30-34 } & 4.49 \\ \text { Age 35-39 } & 4.69 \\ \text { Age 40-44 } & 4.93 \\ \text { Age 45-49 } & 5.07 \\ \text { Age 50-54 } & 4.98 \\ \text { Age 55-59 } & 4.96 \\ \text { Age 60-64 } & 4.91 \\ \text { Age 65-69 } & 5.08 \\ \text { Age 70-74 } & 5.05 \\ \text { Age } 75-79 & 5.01 \\ \text { Age } \geq 80 & 4.91\end{array}$

Women TC (mmol/L)

\begin{tabular}{|c|c|c|c|c|}
\hline Age 18-19 & 3.77 & & & \\
\hline Age 20-24 & 4.01 & & & \\
\hline Age 25-29 & 4.17 & & & \\
\hline Age 30-34 & 4.25 & & & \\
\hline Age 35-39 & 4.4 & & & \\
\hline Age 40-44 & 4.63 & & & \\
\hline Age 45-49 & 4.87 & & & \\
\hline Age 50-54 & 5.22 & & & \\
\hline Age 55-59 & 5.32 & & & \\
\hline Age 60-64 & 5.44 & & & \\
\hline Age 65-69 & 5.57 & & & \\
\hline Age 70-74 & 5.6 & & & \\
\hline Age 75-79 & 5.58 & & & \\
\hline Age $\geq 80$ & 5.41 & & & \\
\hline $\mathrm{BMI}\left(\mathrm{kg} / \mathrm{m}^{2}\right)$ & $\begin{array}{l}\text { Distribution } \\
\text { assumption }\end{array}$ & Mean & SD & 26 \\
\hline BMI of 43.4 years old men & Normal & 25.5 & 3.7 & \\
\hline BMI of 44.3 years old women & Normal & 24.5 & 3.8 & \\
\hline Diabetes prevalence of 18 years old men & $0.11 \%$ & & & 31 \\
\hline Male 1-year diabetes probabilities & & & & 28 \\
\hline Age 20-29 & $0.25 \%$ & & & \\
\hline Age 30-39 & $0.26 \%$ & & & \\
\hline Age 40-49 & $0.61 \%$ & & & \\
\hline Age 50-59 & $0.44 \%$ & & & \\
\hline Age 60-69 & $0.27 \%$ & & & \\
\hline Age 70-79 & $0.38 \%$ & & & \\
\hline
\end{tabular}

Continued

\section{Value}

Distribution

Normal

Normal

126.1

18.2

19.2

3.38

4.26

4.49

4.93

4.96

5.08

5.05

4.91

3.77

4.01

4.17

4.4

4.63

5.22

5.32

5.6

Distribution ssumption

Normal

\section{References} 26 


\begin{tabular}{lcc}
\hline Table 1 Continued & Value & References \\
\hline Risk factor type & $0.38 \%$ & 31 \\
\hline Age $\geq 80$ & $0.11 \%$ & 28 \\
\hline Diabetes prevalence of 18 years old women & & \\
\hline Female 1-year diabetes probabilities & $0.11 \%$ & \\
\hline Age $20-29$ & $0.18 \%$ & \\
Age $30-39$ & $0.44 \%$ & \\
\hline Age $40-49$ & $0.59 \%$ & 28 \\
\hline Age $50-59$ & $0.74 \%$ & 28 \\
\hline Age $60-69$ & $0.17 \%$ & \\
\hline Age $70-79$ & $0.17 \%$ & \\
\hline Age $\geq 80$ & $58.20 \%$ & \\
\hline Male smoking percentage & $3.40 \%$ & \\
\hline Female smoking percentage &
\end{tabular}

BMI, body mass index; SBP, systolic blood pressure; TC, total cholesterol.

standard set the annual average $\mathrm{PM}_{2.5}$ concentration limit at $15 \mu \mathrm{g} / \mathrm{m}^{3}{ }^{34}{ }^{51}$ According to WHO estimates, the HRs of CHD and stroke events associated with the increase of $\mathrm{PM}_{2.5}$ concentration from 15 to $105 \mu \mathrm{g} / \mathrm{m}^{3}$ are 1.27 and 1.74 , respectively. ${ }^{35}$

In addition, one-way sensitivity analyses were conducted for the individual lifetime analysis. Specifically, key input parameters including hospitalisation costs associated with AMI and stroke, 28-day mortality associated with AMI and stroke, and the HR of $\mathrm{PM}_{2.5}$ exposure, smoking rates, and diabetes prevalence/incidence rates were increased or decreased by $15 \%$ in each sensitivity analysis. More, the annual discount rate was adjusted to $5 \%$ and $1 \%$ in a set of sensitivity analyses. Even more, we decreased the population background mortality at each age by $10 \%$ to reflect longer life expectancy in future as a sensitivity analysis. Finally, the base-case QALY results were monetised using once instead of three times the GDP per capita to estimate the NMLs under the alternative WTP. ${ }^{52}$ One-way sensitivity analyses were conducted for male and female individuals separately and the results were summarised using NML.

The model was programmed using Excel 2013 VBA (Microsoft).

\section{Patient and public involvement}

It was not appropriate or possible to involve patients or the public in the design, or conduct, or reporting, or dissemination plans of our research.

\section{RESULTS}

Table 3 lists 1-year excess costs and QALY loss in Beijing population associated with cardiovascular diseases that were attributable to $\mathrm{PM}_{2.5}$ pollution in 2015 . The excess direct costs in male and female Beijing population were US $\$ 87.9$ million and US\$60.1 million, respectively, summing to total excess direct costs of US $\$ 147.9$ million. The QALY loss in male and female Beijing population was 44186 and 48 388. Consequently, the total QALY loss was 92574 . Accordingly, the NML in male, female, and the entire Beijing population was US $\$ 1106.4$ million, US $\$ 1175.4$ million, and US $\$ 2281.8$ million, respectively. Furthermore, the total direct costs of cardiovascular diseases in Beijing was US\$1056.9 million when calculated using our model outputs (not listed in the tables). Hence, about $14 \%$ of direct costs of cardiovascular diseases in Beijing was attributable to $\mathrm{PM}_{2.5}$ pollution.

Table 4 presents expected lifetime excess costs and QALY loss for male and female individuals at the age of 18. The expected incremental costs for a male Beijing adult and female Beijing adult were US\$237 and US\$163. The corresponding QALY loss was 0.14 and 0.12 . Consequently, the NML for an average male and an average female Beijing adult was US $\$ 3514$ and US $\$ 2935$.

As expected, the excess costs and QALY loss using $15 \mu \mathrm{g} /$ $\mathrm{m}^{3}$ as the standard $\mathrm{PM}_{2.5}$ concentration level were greater than using $35 \mu \mathrm{g} / \mathrm{m}^{3}$ as the standard $\mathrm{PM}_{25}$ concentration level. In this alternative scenario, 1-year excess direct costs in male, female and the entire Beijing population were US $\$ 149.6$ million, US $\$ 115.2$ million, and US $\$ 264.8$ million, respectively. The QALY loss in male, female and the entire Beijing population was 81040,71394 , and 152 434, respectively. Hence, the corresponding NML in the three population groups was US\$2017.6 million, US $\$ 1760.9$ million, and US\$3778.5 million. In addition, the expected lifetime excess costs, QALY loss and NML for a male Beijing adult and female Beijing adult using the alternative scenario were US\$364 and US $\$ 275,0.24$ and 0.19 , and US $\$ 5924$ and US $\$ 4763$.

One-way sensitivity analyses results are shown in online supplemental figure S1. In summary, increasing or decreasing discount rate by $2 \%$ had the most prominent impact on the expected individual lifetime NML estimates. Changing the effect of pollution on cardiovascular events by $\pm 15 \%$ also changed the expected individual lifetime NML estimates substantially. By contrast, $\pm 15 \%$ changes 


\begin{tabular}{|c|c|c|c|}
\hline Input type & Value & & References \\
\hline $\begin{array}{l}\text { Annual background } \\
\text { mortality }\end{array}$ & Men & Women & 36 \\
\hline Age 18-19 & $0.009 \%$ & $0.007 \%$ & \\
\hline Age $20-24$ & $0.012 \%$ & $0.011 \%$ & \\
\hline Age 25-29 & $0.013 \%$ & $0.011 \%$ & \\
\hline Age 30-34 & $0.014 \%$ & $0.013 \%$ & \\
\hline Age 35-39 & $0.020 \%$ & $0.017 \%$ & \\
\hline Age $40-44$ & $0.035 \%$ & $0.028 \%$ & \\
\hline Age $45-49$ & $0.059 \%$ & $0.043 \%$ & \\
\hline Age $50-54$ & $0.099 \%$ & $0.070 \%$ & \\
\hline Age 55-59 & $0.176 \%$ & $0.119 \%$ & \\
\hline Age 60-64 & $0.307 \%$ & $0.211 \%$ & \\
\hline Age 65-69 & $0.527 \%$ & $0.373 \%$ & \\
\hline Age $70-74$ & $0.894 \%$ & $0.653 \%$ & \\
\hline Age $75-79$ & $1.484 \%$ & $1.128 \%$ & \\
\hline Age $80-84$ & $2.600 \%$ & $2.063 \%$ & \\
\hline Age 85-89 & $4.223 \%$ & $3.512 \%$ & \\
\hline $\begin{array}{l}28 \text { day post-AMI } \\
\text { mortality }\end{array}$ & Men & Women & 19 \\
\hline $35-44$ & $12 \%$ & $18 \%$ & \\
\hline $45-54$ & $21 \%$ & $23 \%$ & \\
\hline $55-64$ & $29 \%$ & $27 \%$ & \\
\hline $65-74$ & $33 \%$ & $43 \%$ & \\
\hline $75-84$ & $48 \%$ & $51 \%$ & \\
\hline $\begin{array}{l}28 \text { day poststroke } \\
\text { mortality }\end{array}$ & Men & Women & 19 \\
\hline $35-44$ & $25 \%$ & $18 \%$ & \\
\hline $45-54$ & $18 \%$ & $14 \%$ & \\
\hline $55-64$ & $12 \%$ & $15 \%$ & \\
\hline $65-74$ & $20 \%$ & $20 \%$ & \\
\hline $75-84$ & $45 \%$ & $45 \%$ & \\
\hline Age-specific utility & Men & Women & 41 \\
\hline $15-19$ & 0.898 & 0.896 & \\
\hline $20-24$ & 0.888 & 0.882 & \\
\hline $25-29$ & 0.878 & 0.867 & \\
\hline $30-34$ & 0.86 & 0.848 & \\
\hline $35-39$ & 0.848 & 0.832 & \\
\hline $40-44$ & 0.834 & 0.815 & \\
\hline $45-49$ & 0.814 & 0.792 & \\
\hline $50-54$ & 0.793 & 0.772 & \\
\hline $55-59$ & 0.774 & 0.752 & \\
\hline $60-64$ & 0.751 & 0.728 & \\
\hline $65-69$ & 0.725 & 0.702 & \\
\hline $70-74$ & 0.701 & 0.685 & \\
\hline $75-79$ & 0.684 & 0.669 & \\
\hline $80-84$ & 0.662 & 0.655 & \\
\hline 85-89 & 0.661 & 0.643 & \\
\hline
\end{tabular}

Continued

\begin{tabular}{|c|c|c|c|}
\hline Input type & \multicolumn{2}{|l|}{ Value } & References \\
\hline $\begin{array}{l}\text { One-month acute } \\
\text { disutility }\end{array}$ & \multicolumn{2}{|c|}{ Men and women } & 42 \\
\hline AMI & \multicolumn{2}{|l|}{0.439} & \\
\hline Stroke & \multicolumn{2}{|l|}{0.920} & \\
\hline $\begin{array}{l}\text { Postevent long-term } \\
\text { disutility }\end{array}$ & \multicolumn{2}{|c|}{ Men and women } & 4243 \\
\hline AMI & \multicolumn{2}{|l|}{0.107} & \\
\hline Stroke & \multicolumn{2}{|l|}{0.266} & \\
\hline Unstable angina & \multicolumn{2}{|l|}{0.124} & \\
\hline \multirow[t]{2}{*}{ Costs (in 2018 CNY) } & \multicolumn{2}{|c|}{ Men and women } & \\
\hline & $\begin{array}{l}\text { AMI and } \\
\text { unstable } \\
\text { angina }\end{array}$ & Stroke & \\
\hline $\begin{array}{l}\text { Hospitalisation costs } \\
\text { (2015 US\$) }\end{array}$ & US\$2630 & US\$1977 & 64 \\
\hline $\begin{array}{l}\text { First year long-term } \\
\text { costs (2015 US\$) }\end{array}$ & US\$602 & US\$369 & 19 \\
\hline $\begin{array}{l}\text { Office visit costs in } \\
\text { subsequent years } \\
\text { (2015 US\$) }\end{array}$ & US\$66 & US\$77 & 65 \\
\hline
\end{tabular}

AMI, acute myocardial infarction.

in hospitalisation costs, 28-day mortality associated with $\mathrm{AMI}$ and stroke, smoking rates and diabetes prevalence/ incidence rates did not have substantial impacts on the expected individual lifetime NML estimates. Similarly, decreasing background mortality by $10 \%$ caused modest changes in results. When once the GDP per capita was used to monetise the QALYs (online supplementary materials part 10 , online supplemental table S5), the NML among men, women and the entire adult population for 1 year was US $\$ 421.4$ million, US $\$ 437.8$ million and US\$859.2 million. The expected lifetime NML for a male Beijing and female Beijing adult under the alternative WTP was US\$1329 and US\$1087, respectively.

\section{DISCUSSION}

We found that $\mathrm{PM}_{2.5}$-related cardiovascular diseases imposed high direct and indirect economic burden on both the entire Beijing population and each Beijing individual during the lifetime course. Consequently, the total economic loss associated with cardiovascular diseases due to $\mathrm{PM}_{2.5}$ was substantial. The NML that was attributable to $\mathrm{PM}_{2.5}$-related cardiovascular diseases in the base-case scenario accounted for $0.68 \%$ of Beijing GDP. ${ }^{53}$ Our results also suggested that QALY loss contributed more than direct medical costs by a sizeable margin to the NML associated with $\mathrm{PM}_{25}$ pollution in Beijing. In addition, $\mathrm{PM}_{2.5}$ pollution accounted for $14 \%$ of direct medical costs of cardiovascular diseases in Beijing. More, the NML further increased by over $60 \%$ if the standard $\mathrm{PM}_{2,5}$ concentration level was $15 \mu \mathrm{g} / \mathrm{m}^{3}$ instead of $35 \mu \mathrm{g} / \mathrm{m}^{3}$. Hence, it is important to note that additional economic 
Table 3 Excess costs and QALY loss in Beijing population associated with cardiovascular diseases that are attributable to $\mathrm{PM}_{25}$ ambient air pollution in 2015

\begin{tabular}{|c|c|c|c|}
\hline & $\begin{array}{l}\text { Excess } \\
\text { costs }^{*} \\
\text { (million) }\end{array}$ & QALY loss $†$ & $\begin{array}{l}\text { NML‡ } \\
\text { (million) }\end{array}$ \\
\hline \multicolumn{4}{|l|}{ Male } \\
\hline Age 18-19 & US\$0.3 & 30 & US\$1.0 \\
\hline Age 20-24 & US\$0.7 & 371 & US\$9.2 \\
\hline Age 25-29 & US\$2.8 & 2598 & US\$62.7 \\
\hline Age 30-34 & US\$2.2 & 1395 & US\$34.4 \\
\hline Age 35-39 & US\$4.0 & 2795 & US\$68.4 \\
\hline Age 40-44 & US\$4.5 & 2942 & US\$72.3 \\
\hline Age 45-49 & US\$6.5 & 3043 & US\$76.7 \\
\hline Age 50-54 & US\$8.3 & 2610 & US\$68.5 \\
\hline Age 55-59 & US\$6.1 & 3881 & US\$95.6 \\
\hline Age 60-64 & US\$12.5 & 4160 & US\$108.4 \\
\hline Age 65-69 & US\$5.2 & 4697 & US\$113.5 \\
\hline Age $70-74$ & US\$7.0 & 4774 & US\$117.0 \\
\hline Age 75-79 & US\$12.2 & 4730 & US\$121.3 \\
\hline Age 80-84 & US\$10.1 & 4699 & US\$118.5 \\
\hline Age 85-89 & US\$5.4 & 1461 & US\$39.1 \\
\hline Male total & US\$87.9 & 44186 & US\$1106.4 \\
\hline \multicolumn{4}{|l|}{ Female } \\
\hline Age 18-19 & US\$0.1 & 1 & US\$0.1 \\
\hline Age 20-24 & US\$0.4 & 175 & US\$4.4 \\
\hline Age 25-29 & US\$0.6 & 246 & US\$6.3 \\
\hline Age 30-34 & US\$0.7 & 415 & US\$10.3 \\
\hline Age 35-39 & US\$0.6 & 359 & US\$8.9 \\
\hline Age 40-44 & US\$0.7 & 581 & US\$14.1 \\
\hline Age 45-49 & US\$1.9 & 701 & US\$18.1 \\
\hline Age 50-54 & US\$4.5 & 3215 & US\$78.6 \\
\hline Age 55-59 & US\$8.0 & 4458 & US\$110.7 \\
\hline Age 60-64 & US\$5.7 & 4169 & US\$101.8 \\
\hline Age 65-69 & US\$7.9 & 4837 & US\$119.4 \\
\hline Age 70-74 & US\$8.3 & 5610 & US\$137.6 \\
\hline Age 75-79 & US\$7.2 & 9891 & US\$235.2 \\
\hline Age 80-84 & US\$6.4 & 7853 & US\$187.4 \\
\hline Age 85-89 & US\$7.0 & 5878 & US\$142.5 \\
\hline Female total & US\$60.1 & 48388 & US\$1175.4 \\
\hline Total & US\$147.9 & 92574 & US\$2281.8 \\
\hline
\end{tabular}

*Excess costs were the difference between the costs of the population (or the population in a certain age group) when exposed to the $\mathrm{PM}_{25}$ concentration of $105 \mu \mathrm{g} / \mathrm{m}^{3}$ and the costs of the same population when exposed to the $\mathrm{PM}_{25}$ concentration of $35 \mu \mathrm{g} / \mathrm{m}^{3}$.

TQALY loss was the difference between the QALYs of the population (or the population in a certain age group) when exposed to the $\mathrm{PM}_{2.5}$ concentration of $35 \mu \mathrm{g} / \mathrm{m}^{3}$ and the QALYs of the same population when exposed to the $\mathrm{PM}_{2.5}$ concentration of $105 \mu \mathrm{g} / \mathrm{m}^{3}$.

†NML was the sum of excess costs and monetised QALY loss. NML, net monetary loss; PM, particulate matter; QALY, quality-

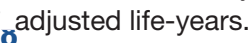

benefit should be expected if $\mathrm{PM}_{2.5}$ concentration can be further reduced to below $15 \mu \mathrm{g} / \mathrm{m}^{3}$.

All Chinese cities have a target of controlling $\mathrm{PM}_{2.5}$ concentration at or below $35 \mu \mathrm{g} / \mathrm{m}^{3}$ by $2030 .{ }^{54}$ Beijing spends around US $\$ 3$ billion annually to reduce air pollution in the recent years. ${ }^{556}$ Our results suggest that the incremental net monetary benefit from decreased cardiovascular diseases alone can offset over two-thirds of the spending if the $\mathrm{PM}_{2.5}$ concentration can be reduced to 35 $\mu \mathrm{g} / \mathrm{m}^{3}$ and offsets the total spending if the $\mathrm{PM}_{2.5}$ concentration can be reduced to $15 \mu \mathrm{g} / \mathrm{m}^{3}$. The economic benefit of reduced air pollution will be substantially greater if the avoided loss in future is considered. Even more, reduced pollution can result in cost savings in other disease areas. As such, the cumulative monetary benefit will likely outweigh the investment eventually, if not immediately. Therefore, continuing the current efforts or even expanding the efforts to aggressively reduce the $\mathrm{PM}_{2.5}$ concentration should be considered.

The current study has several strengths and weaknesses. Using a health economic modelling approach, the current study could estimate cardiovascular disease burden associated with long-term exposure to $\mathrm{PM}_{25}$ pollution in terms of costs and QALYs. We know of one study that estimated chronic kidney disease-related disability-adjusted life year burden that was attributable to ambient air pollution using population-level reweighting. ${ }^{57}$ However, we know of no other studies that used economic simulations to approach such issues. The economic modelling approach may be appealing to researchers by affording the opportunity to evaluate both population-level disease burden in a period and individual residual lifetime disease burden imposed by $\mathrm{PM}_{2.5}$ pollution. The population estimates gave a snapshot of the economic burden in 2015, whereas the individual expected lifetime estimates took into account the longitudinal excess costs and QALY loss. More, the model allowed exploration of various scenarios, which was not possible using retrospective data analysis. In fact, the simulation tool that we developed can be adapted to explore other scenarios than the ones already examined should it be necessary for interested parties to change input parameters. Finally, we chose microsimulation over the common practice of Markov cohort state-transition model. Compared with the latter, the former allows multiple events in one cycle and keeps track of disease history of each simulated individual. ${ }^{165}$ Failure to account for multiple events per cycle may lead to downward bias of the burden of ambient air pollution since a fraction of the adverse outcomes might not be reflected in the model.

Potential limitations should be considered when interpreting our results. Economic modelling has an innate limitation of making assumptions about data and course of action, and sensitivity analyses cannot examine model robustness to each assumption. One of the strong assumptions we made was that the population under investigation had been continuously exposed to $\mathrm{PM}_{25}$ pollution to experience the adverse effects and would still be exposed in their residual lifetime. 
Table 4 Expected lifetime excess costs and QALY loss of an 18-year-old Beijing male individual and an 18-year-old Beijing female individual associated with cardiovascular diseases that are attributable to $\mathrm{PM}_{2.5}$ ambient air pollution in 2015

\begin{tabular}{|c|c|c|c|}
\hline & $\begin{array}{l}\text { Current } \mathrm{PM}_{2.5} \\
\text { concentration } \\
\left(105 \mu \mathrm{g} / \mathrm{m}^{3}\right)\end{array}$ & $\begin{array}{l}\mathrm{PM}_{2.5} \text { concentration at } \\
35 \mu \mathrm{g} / \mathrm{m}^{3}\end{array}$ & Difference \\
\hline \multicolumn{4}{|l|}{ Male } \\
\hline $\begin{array}{l}\text { Expected lifetime costs associated with cardiovascular } \\
\text { disease }\end{array}$ & US\$1692 & US\$1455 & US\$237 \\
\hline Expected lifetime QALYs & 23.49 & 23.63 & -0.14 \\
\hline Net monetary benefit & US\$539 802 & US\$543 316 & -US\$3514 \\
\hline \multicolumn{4}{|l|}{ Female } \\
\hline $\begin{array}{l}\text { Expected lifetime costs associated with cardiovascular } \\
\text { disease }\end{array}$ & US\$1247 & US\$1084 & US\$163 \\
\hline Expected lifetime QALYs & 23.49 & 23.61 & -0.12 \\
\hline Net monetary benefit & US\$540 259 & US\$543 194 & -US\$2935 \\
\hline
\end{tabular}

.PM, particulate matter; QALY, quality-adjusted life-years.;

In other words, we assumed the population of interest was static. Numerous studies have considered exposures of at least 9-12 months in duration as long term. ${ }^{59}$ However, the demographic structure is in fact highly dynamic and a small fraction of the population may migrate between low pollution and high pollution regions even within a 9-month period. This assumption affected all results of the current study including population 1-year estimates and individual expected lifetime estimates. Another noteworthy assumption was associating $\mathrm{PM}_{2.5}$ cardiovascular effects with annual average $\mathrm{PM}_{2.5}$ concentration. We used the annual average to be compliant with available effect estimates in the literature. However, the actual long-term effect of $\mathrm{PM}_{2.5}$ pollution on cardiovascular diseases may not necessarily be represented by annual average concentration. The model was additionally based on several assumptions which are listed in online supplementary materials part 11 online supplemental table S6. In addition, the current study examined the economic burden associated with long-term exposure to $\mathrm{PM}_{2.5}$, but not short-term exposure. Short-term exposure also has cardiovascular effects. ${ }^{8}$ Unfortunately, it is not technically feasible to model both long-term effects and shortterm effects in one model since the simulation advances at a chosen time unit (yearly increment in the current study) and the time unit cannot accommodate both long-term and short-term effects. More, despite that focusing on cardiovascular diseases provided insights into certain aspects, it also limited the understanding of overall burden. Even more, the current study investigated the cardiovascular disease outcomes associated with $\mathrm{PM}_{2.5}$, but not other air pollutants such as $\mathrm{PM}_{10-2.5}$. We focused on $\mathrm{PM}_{2.5}$ because of the relatively well-established epidemiology evidence on $\mathrm{PM}_{2.5}$ and the fact that the combined health effect of air pollutants on cardiovascular events is not well understood at present. ${ }^{7}$ Although some evidence suggests that the finest $\mathrm{PM}_{2.5}$ has a stronger cardiovascular effect than the relatively coarse $\mathrm{PM}_{10-2.5}$, the effect of $\mathrm{PM}_{10-2.5}$ is nontrivial. ${ }^{8}$ Therefore, it is reasonable to expect that the economic burden of cardiovascular diseases is even greater than that estimated in the current study if the effects of other air pollutants are considered. Finally, the IER estimates in the analysis were not necessarily up to date. However, the relatively recent estimates of 2016 GBD were only presented for concentration intervals, failing the need of calculating HRs based on exact concentrations.

To our best knowledge, the current study represents the first attempt to estimate both economic and humanistic burden associated with $\mathrm{PM}_{2.5}$-related cardiovascular diseases of any area. Thus, the current study is not directly comparable to results from existing studies in the literature. However, previous studies estimated that the total direct and indirect economic loss due to $\mathrm{PM}_{9}$ pollution accounted for $0.76 \%-2.75 \%$ of Beijing GDP. ${ }^{11^{2} \cdot 51}$ By including QALY loss in the calculation, we estimated that the NML due to cardiovascular diseases alone associated with $\mathrm{PM}_{2.5}$ pollution accounted for $0.68 \%$ of Beijing GDP. Although the estimates are not directly comparable, they provide face validity to each other. These numbers also resonate the estimates in the UK where the burden of air pollution in monetary terms was equivalent to $1.5 \%$ of GDP. ${ }^{62}$ Beyond monetary terms and cardiovascular diseases, Bowe et al has shown $\mathrm{PM}_{25}$ caused about 6.6 million disability-adjusted life years globally per annum due to chronic kidney diseases. These estimates, put together with the present findings, suggest that much remains to be done to reduce the disease burden of ambient air pollution.

Future research should accomplish two immediate tasks in the near term. First, similar models should be developed to estimate direct costs and QALY loss of other diseases to which the contribution of $\mathrm{PM}_{2.5}$ is strongly supported by epidemiology evidence including but not limited to chronic obstructive pulmonary disease, lung cancer and acute lower respiratory infections. ${ }^{63}$ This exercise will help to provide additional insights on the disease-specific economic burden of $\mathrm{PM}_{2.5}$ pollution. Second, analyses of the economic burden of cardiovascular diseases caused by $\mathrm{PM}_{2.5}$ pollution should expand to other regions in China as well as other low-income 
and middle-income countries that have similarly high levels of air pollution. In 2015, 165 out 190 priority pollution monitoring cities in China did not meet the CAAQS Grade II standard of annual average $\mathrm{PM}_{2.5}$ concentration, ${ }^{9}$ which highlights the importance of expanding the analysis to other areas since the total economic burden of cardiovascular diseases caused by $\mathrm{PM}_{2.5}$ pollution in the broader population is expected to be much higher than that of Beijing alone.

\section{CONCLUSIONS}

$\mathrm{PM}_{2.5}$-related cardiovascular diseases lead to substantial excess medical costs and QALY loss in Beijing adult population. Intensive and effective initiatives to reduce the $\mathrm{PM}_{2.5}$ concentration to $35 \mu \mathrm{g} / \mathrm{m}^{3}$ or even lower levels should be considered by policymakers to reduce the burden of cardiovascular diseases in Beijing.

Contributors Conceptualisation, design, data collection, analysis, programming and writing: $\mathrm{YJ}$; analysis and manuscript revision: $\mathrm{SJ}$; data collection, analysis and manuscript revision: WN.

Funding The authors have not declared a specific grant for this research from any funding agency in the public, commercial or not-for-profit sectors.

Competing interests None declared.

Patient consent for publication Not required.

Provenance and peer review Not commissioned; externally peer reviewed.

Data availability statement The data analysed during the study are presented in the article and its online supplemental materials. The program and code that were used in the present study have been provided for editorial and peer review and are available from the corresponding author on reasonable requests.

Supplemental material This content has been supplied by the author(s). It has not been vetted by BMJ Publishing Group Limited (BMJ) and may not have been peer-reviewed. Any opinions or recommendations discussed are solely those of the author(s) and are not endorsed by BMJ. BMJ disclaims all liability and responsibility arising from any reliance placed on the content. Where the content includes any translated material, BMJ does not warrant the accuracy and reliability of the translations (including but not limited to local regulations, clinical guidelines, terminology, drug names and drug dosages), and is not responsible for any error and/or omissions arising from translation and adaptation or otherwise.

Open access This is an open access article distributed in accordance with the Creative Commons Attribution Non Commercial (CC BY-NC 4.0) license, which permits others to distribute, remix, adapt, build upon this work non-commercially, and license their derivative works on different terms, provided the original work is properly cited, appropriate credit is given, any changes made indicated, and the use is non-commercial. See: http://creativecommons.org/licenses/by-nc/4.0/.

\section{ORCID iDs}

Yawen Jiang http://orcid.org/0000-0002-0498-0662

Shan Jiang http://orcid.org/0000-0003-1015-1278

\section{REFERENCES}

1 Wong CM, Lai HK, Tsang H, et al. Satellite-Based estimates of long-term exposure to fine particles and association with mortality in elderly Hong Kong residents. Environ Health Perspect 2015;123:1167-72.

2 Burnett RT, Pope CA, Ezzati M, et al. An integrated risk function for estimating the global burden of disease attributable to ambient fine particulate matter exposure. Environ Health Perspect 2014;122:397-403.

3 Lim SS, Vos T, Flaxman AD, et al. A comparative risk assessment of burden of disease and injury attributable to 67 risk factors and risk factor clusters in 21 regions, 1990-2010: a systematic analysis for the global burden of disease study 2010. The Lancet 2012;380:2224-60.

4 Apte JS, Marshall JD, Cohen AJ, et al. Addressing global mortality from ambient PM2.5. Environ Sci Technol 2015;49:8057-66.
5 Ouyang Y. China wakes up to the crisis of air pollution. Lancet Respir Med 2013:1:12.

6 Dai S, Xu L. More than nine in 10 Chinese cities exceeded air pollution targets in 2014, says Greenpeace. BMJ 2015;350:h590.

7 Brook RD, Rajagopalan S, Pope CA, et al. Particulate matter air pollution and cardiovascular disease. Circulation 2010;121:2331-78.

8 Martinelli N, Olivieri O, Girelli D. Air particulate matter and cardiovascular disease: a narrative review. Eur J Intern Med 2013;24:295-302.

9 Zhang Y-L, Cao F. Fine particulate matter (PM 2.5) in China at a City level. Sci Rep 2015;5:14884.

10 Gao M, Guttikunda SK, Carmichael GR, et al. Health impacts and economic losses assessment of the 2013 severe haze event in Beijing area. Sci Total Environ 2015;511:553-61.

$11 \mathrm{Du} \mathrm{Y,} \mathrm{Li} \mathrm{T.} \mathrm{Assessment} \mathrm{of} \mathrm{health-based} \mathrm{economic} \mathrm{costs} \mathrm{linked}$ to fine particulate (PM2.5) pollution: a case study of haze during January 2013 in Beijing, China. Air Qual Atmos Health 2016;9:439-45.

12 Weinstein MC, Torrance G, McGuire A. QALYs: the basics. Value Health 2009;12 Suppl 1:S5-9.

13 Fu A. On the issue of utility multiplication: predicting joint healthstates utility. ISPOR Connections 2009;15:4-5.

14 Husereau D, Drummond M, Petrou S, et al. Consolidated Health Economic Evaluation Reporting Standards (CHEERS)--explanation and elaboration: a report of the ISPOR Health Economic Evaluation Publication Guidelines Good Reporting Practices Task Force. Value Health 2013;16:231-50.

15 Bleibler F, Rapp K, Jaensch A, et al. Expected lifetime numbers and costs of fractures in postmenopausal women with and without osteoporosis in Germany: a discrete event simulation model. BMC Health Serv Res 2014;14:284.

16 Caro JJ, Möller J, Getsios D. Discrete event simulation: the preferred technique for health economic evaluations? Value Health 2010;13:1056-60.

17 Karnon J, Stahl J, Brennan A, et al. Modeling using discrete event simulation: a report of the ISPOR-SMDM modeling good research practices task Force-4. Med Decis Making 2012;32:701-11.

18 Gaziano TA, Opie LH, Weinstein MC. Cardiovascular disease prevention with a multidrug regimen in the developing world: a costeffectiveness analysis. Lancet 2006;368:679-86.

$19 \mathrm{Gu}$ D, He J, Coxson PG, et al. The cost-effectiveness of low-cost essential antihypertensive medicines for hypertension control in China: a modelling study. PLoS Med 2015;12:e1001860.

20 Smith-Spangler CM, Juusola JL, Enns EA, et al. Population strategies to decrease sodium intake and the burden of cardiovascular disease: a cost-effectiveness analysis. Ann Intern Med 2010;152:481-7.

21 Wang M, Moran AE, Liu J, et al. Cost-Effectiveness of optimal use of acute myocardial infarction treatments and impact on coronary heart disease mortality in China. Circ Cardiovasc Qual Outcomes 2014;7:000674

22 Jiang Y, Ni W. Economic evaluation of the 2016 Chinese guideline and alternative risk thresholds of initiating statin therapy for the management of atherosclerotic cardiovascular disease. Pharmacoeconomics 2019;37:943-52.

23 Wu Y, Liu X, Li X, et al. Estimation of 10-year risk of fatal and nonfatal ischemic cardiovascular diseases in Chinese adults. Circulation 2006;114:2217-25.

24 Beck JR, Pauker SG, Gottlieb JE, et al. A convenient approximation of life expectancy (the "DEALE"). II. Use in medical decision-making. Am J Med 1982;73:889-97.

25 Wu F, Guo Y, Kowal P, et al. Prevalence of major chronic conditions among older Chinese adults: the study on global ageing and adult health (SAGE) wave 1. PLoS One 2013;8:e74176.

26 Cai L, Liu A, Zhang Y, et al. Waist-to-height ratio and cardiovascular risk factors among Chinese adults in Beijing. PLoS One 2013;8:e69298.

27 Li Z, Yang R, Xu G, et al. Serum lipid concentrations and prevalence of dyslipidemia in a large professional population in Beijing. Clin Chem 2005;51:144-50.

28 Yang Z-J, Liu J, J-P G, et al. Prevalence of cardiovascular disease risk factor in the Chinese population: the 2007-2008 China national diabetes and metabolic disorders study.. Eur Heart J 2011:ehr205.

29 Jaacks LM, Gordon-Larsen P, Mayer-Davis EJ, et al. Age, period and cohort effects on adult body mass index and overweight from 1991 to 2009 in China: the China health and nutrition survey. Int $J$ Epidemiol 2013;42:828-37.

30 Zhao Y, Hu Y, Smith JP, et al. Cohort profile: the China health and retirement longitudinal study (CHARLS). Int J Epidemiol 2014;43:61-8. 
31 Fu J-F, Liang L, Gong C-X, et al. Status and trends of diabetes in Chinese children: analysis of data from 14 medical centers. World $J$ Pediatr 2013;9:127-34.

32 Yang J, Fu Q, Guo X, et al. Concentrations and seasonal variation of ambient $\mathrm{PM}(2.5)$ and associated metals at a typical residential area in Beijing, China. Bull Environ Contam Toxicol 2015;94:232-9.

33 Guo Y, Li S, Tian Z, et al. The burden of air pollution on years of life lost in Beijing, China, 2004-08: retrospective regression analysis of daily deaths. BMJ 2013;347:f7139.

34 Wang Y, Ying Q, Hu J, et al. Spatial and temporal variations of six criteria air pollutants in 31 provincial capital cities in China during 2013-2014. Environ Int 2014;73:413-22.

35 World Health Organization. Global Burden of Disease Study (GBD 2010) - Ambient Air Pollution Risk Model 1990 - 2010 Seattle, United States: Institute for Health Metrics and Evaluation (IHME), 2013. Available: http://ghdx.healthdata.org/record/global-burden-diseasestudy-2010-gbd-2010-ambient-air-pollution-risk-model-1990-2010 [Accessed 20 Nov 2015].

36 World Health Organization. Life tables by country China, 2013. Available: http://apps. who.int/gho/data/?theme=main\&vid=60340 [Accessed 08 Oct 2015].

37 Moran A, Zhao D, Gu D, et al. The future impact of population growth and aging on coronary heart disease in China: projections from the coronary heart disease policy Model-China. BMC Public Health 2008;8:394.

38 Greving JP, Buskens E, Koffijberg H, et al. Cost-Effectiveness of aspirin treatment in the primary prevention of cardiovascular disease events in subgroups based on age, gender, and varying cardiovascular risk. Circulation 2008;117:2875-83.

39 National Bureau of Statistics of China. Consumer price indices, healthcare, 2015. Available: http://data.stats.gov.cn/english/adv. htm?m=advquery\&cn=A01 [Accessed 17 Oct 2015].

40 International Monetary Fund. Exchange rate Archives, 2015. Available: https://www.imf.org/external/np/fin/data/param_rms_mth. aspx [Accessed 17 Oct 2015].

41 Sun S, Chen J, Johannesson M, et al. Population health status in China: EQ-5D results, by age, sex and socio-economic status, from the National health services survey 2008. Qual Life Res 2011;20:309-20.

42 World Health Organization. Global burden of disease 2004 update: disability weights for diseases and conditions Geneva, Switzerland: World Health organization, 2004. Available: http://www.who.int/ healthinfo/global_burden_disease/GBD2004_DisabilityWeights.pdf [Accessed 13 Oct 2015].

43 Tan Z, Liang Y, Liu S, et al. Health-Related quality of life as measured with EQ-5D among populations with and without specific chronic conditions: a population-based survey in Shaanxi Province, China. PLoS One 2013;8:e65958.

44 Beijing Municipal Bureau of Statistics. Permant population (19782014), 2014. Available: http://www.bjstats.gov.cn/English/MR/ Population/201603/t20160303_337912.html [Accessed 20 Oct 2015].

45 Beijing Municipal Bureau of Statistics. Permanent residents age-sex pyramid, 2010. Available: http://www.bjstats.gov.cn/rkjd/ [Accessed 20 October 2015].

46 Severens JL, Milne RJ. Discounting health outcomes in economic evaluation: the ongoing debate. Value Health 2004;7:397-401.

47 Edejer TT-T, Baltussen R, Adam T, et al. WHO guide to costeffectiveness analysis. Geneva: World Health Organization, 2002.
48 Adler MD. QALYs and policy evaluation: a new perspective. Yale $J$ Health Policy Law Ethics 2006;6:1.

49 The World Bank. GDP per capita (current US\$), 2014. Available: http://data. worldbank.org/indicator/NY.GDP.PCAP.CD?locations=CN [Accessed 14 Oct 2015].

50 Marseille E, Larson B, Kazi DS, et al. Thresholds for the costeffectiveness of interventions: alternative approaches. Bull World Health Organ 2015;93:118-24.

51 United States Environmental Protection Agency. Particulate Matter (PM) Standards - Table of Historical PM NAAQS, 2016. Available: https://www3.epa.gov/ttn/naaqs/standards/pm/s_pm_history.html\#2 [Accessed 27 Aug 2017].

52 Robinson LA, Hammitt JK, Chang AY, et al. Understanding and improving the one and three times GDP per capita costeffectiveness thresholds. Health Policy Plan 2017;32:czw096

53 IEIS. A comparative study on the competitiveness of the film industries between Beijing and London based on the new diamond model. International Conference on Industrial Economics System and Industrial Security Engineering 24-27 Jul 2016, 2016.

54 Wang L, Zhang F, Pilot E, et al. Taking action on air pollution control in the Beijing-Tianjin-Hebei (BTH) region: progress, challenges and opportunities. Int J Environ Res Public Health 2018;15:306.

55 The People's Repbulic of China The State Council. Beijing to spend billions to tackle air pollution in 2017,2017 . Available: http://english. gov.cn/news/top_news/2017/01/15/content_281475542107068.htm [Accessed 29 Mar 2017].

56 Li F. China's provincial governments step up efforts in environmental protection, 2018. Available: http://www.xinhuanet. com/english/2018-02/01/c_136942383.htm [Accessed 26 Mar 2018].

57 Bowe B, Artimovich E, Xie Y, et al. The global and national burden of chronic kidney disease attributable to ambient fine particulate matter air pollution: a modelling study. BMJ Glob Health 2020;5:e002063.

58 Caro JJ. Pharmacoeconomic analyses using discrete event simulation. Pharmacoeconomics 2005;23:323-32.

59 Liu C, Yang C, Zhao Y, et al. Associations between long-term exposure to ambient particulate air pollution and type 2 diabetes prevalence, blood glucose and glycosylated hemoglobin levels in China. Environ Int 2016;92-93:416-21.

60 Madrigano J, Kloog I, Goldberg R, et al. Long-Term exposure to PM2.5 and incidence of acute myocardial infarction. Environ Health Perspect 2013;121:192-6.

61 Xie Y, Dai H, Dong H, et al. Economic impacts from PM2.5 PollutionRelated health effects in China: a Provincial-Level analysis. Environ Sci Technol 2016;50:4836-43.

62 Williams ML, Beevers S, Kitwiroon N, et al. Public health research. public health air pollution impacts of pathway options to meet the 2050 UK climate change act target: a modelling study. Southampton (UK): NIHR Journals Library, 2018.

63 Zheng S, Pozzer A, Cao CX, et al. Long-term (2001-2012) concentrations of fine particulate matter $(\mathrm{PM}<\mathrm{sub}>2.5</$ sub $>)$ and the impact on human health in Beijing, China. Atmos Chem Phys 2015;15:5715-25.

64 Wang S, Petzold M, Cao J, et al. Direct medical costs of hospitalizations for cardiovascular diseases in Shanghai, China: trends and projections. Medicine 2015;94:e837.

65 Zhao W, Zhai Y, Hu J, et al. Economic burden of obesity-related chronic diseases in mainland China. Obes Rev 2008;9 Suppl 1:62-7. 